\title{
Virtue Ethics, Kantian Ethics and Consequentialism
}

\section{$\underline{\text { Introduction }}$}

Contemporary theories of Virtue Ethics are often presented as theories that are in opposition to Kantian Ethics and Consequentialist Ethics. One reason that is commonly put forward to justify this opposition is that they take different moral questions to be the central or fundamental moral question. Virtue ethics takes character to be at the centre of morality making the fundamental moral question, "What sort of character would the virtuous person have?” On the other hand, it would appear that Consequentialist Ethics and Kantian Ethics take as primary the question, "What makes an action right?"

Stating the opposition in this way still leaves the precise nature of the opposition unclear. Assuming that it is correct to suppose that they locate the central moral questions in different areas leaves it an open question whether or not the opposing theories provide an answer to the questions that they do not take to be fundamental. Is there an answer within Virtue Ethics to the question, "What makes an action right" and within Consequentialist and Kantian Ethics to the question , "What sort of character would the virtuous person have?”

However, it might be claimed that none of these theories are able to answer both questions. Robert Louden argues for the claim "that we need to begin efforts to coordinate irreducible or strong notions of virtue along with irreducible or strong conceptions of the various act notions into our conceptual scheme of morality”i The idea then would be that we do not have Virtue Ethics necessarily in competition with 
Kantian Ethics and Consequentialist Ethics. Rather, some sort of combination of theories dealing with the questions of what character a virtuous person would have and what makes an action right could be proposed.

In a recent book covering all three of these approaches, Marcia Baron claims, "it is difficult to see what all three are theories of. Are they theories of what makes an action right? That would not be an accurate way to characterise virtue ethics...I doubt that there is anything that all three are theories of."ii Pettit in the same volume disagrees with this view arguing that there are some questions for which all three theories provide answers. However, he also argues that Consequentialism only answers one question and therefore, "from the consequentialist point of view, Kantianism and virtue ethics may have much to teach. All that it necessarily opposes is any suggestion that the right option is sometimes fixed on some basis other than that it is the option that maximises expected value.”iii

Pettit's view then is that Consequentialism is just designed to answer the question of justifying the right option. Consequentialism is described as "virtual consequentialism,iv since it only provides an answer to this one ethical question and is silent on questions about how we should decide on what we ought to do, what motives we ought to have and what sort of person we should try to be. Since Virtue Ethics and Kantian Ethics consider some of these other questions, Pettit's suggestion appears to be that some sort of combination of views may therefore be possible. In the light of these differing interpretations, I shall start by trying to locate what could be taken to be the essence of these three approaches. In this way we can gain a clearer 
idea of the choice between these three approaches and locate differences between them.

\section{The essences of the three approaches}

To begin with, it is not possible to claim that the difference between Virtue Ethics on the one hand and Kantian Ethics and Consequentialism on the other is that Virtue Ethics is not a theory about what makes an action right. Baron is wrong to suggest this since Virtue Ethics does provide a characterisation of what counts as a right action. Hursthouse writes, “An action is right iff it is what a virtuous agent would characteristically (i.e. acting in character) do in the circumstances.”

However, what is at issue here is not whether Virtue Ethics can provide an answer to the question of what makes an action right but where the different theories locate their essence. It might be the case that the essence of Consequentialism limits it to just answering the question of the justification of the right option but the essence of Virtue Ethics and Kantian Ethics does not necessarily imply their silence on answers to other ethical questions.

A more profitable place to look to capture the essence of the difference between the three theories is rather in the question, what do they take the central ethical activity to be. What I have in mind here is to isolate the central activity that is necessary for the operation of the theory at all. In the case of Virtue Ethics, the development of a virtuous character is necessary before we can identify what a right action would be. This is evident in Hursthouse's characterisation quoted above. In Kantian Ethics, the development of a good will is necessary for the performance of right actions. Kant 
writes, "reason recognises as its highest practical function the establishment of a good will.”v Now, the interesting point about Consequentialism is that no such central activity is proposed. It is left an open question what needs to be done in order that outcomes be maximised.

This focus on the debate suggests an alignment where Virtue Ethics and Kantian Ethics are grouped together in contrast to Consequentialism. This immediately shifts what has been taken to be the central contrast in contemporary literature between Virtue Ethics, on the one hand, and Kantian and Consequentialist Ethics on the other. The suggestion that I should like to consider is that the central activities are as follows

Virtue Ethics: The development of a virtuous character

Kantian Ethics: The development of a good will

Consequentialist Ethics: No central activity is specified. This is an open question to be decided in terms of what would maximise the best outcomes.

In what follows, I shall justify and elaborate these claims and then provide an evaluation of these theories interpreted in this way. Consequentialism will be seen to have very little to offer in the reduced form which captures its essence. It also cannot be enriched by combination with features from Virtue Ethics and Kantian Ethics as Pettit suggests.

The evaluation of Virtue Ethics and Kantian Ethics will centre on an important contrast between how these theories interpret what I take to be their central ethical activity. Although both theories have at their centre self development in terms of a 
good character or good will, Virtue Ethics only allows contingently for the recognition that others are also developing their own character. Kantian Ethics , I will argue, recognises this necessarily. Therefore, although my characterisation of Virtue Ethics and Kantian Ethics appears to leave these open to the criticism of selfcentredness, this will be shown to be a criticism that Virtue Ethics could possibly avoid but which Kantian Ethics necessarily does avoid.

\section{Consequentialism}

The essence of Consequentialism can be captured in Parfit's characterisation of it as, "There is one ultimate moral aim: that outcomes be as good as possible»vi Although this statement of Consequentialism ties Consequentialism to a maximising form which it might be argued is not essential to Consequentialism ${ }^{\mathrm{vii}}$, in all other respects it captures the heart of Consequentialism. Consequentialism is essentially a justificatory doctrine. It does not tell us explicitly what motivational doctrine we ought to adopt over and above the claim that it should be the motivational doctrine that will make outcomes as good as possible. It does not indicate whether we should consider individual acts separately or rules. What will justify our choice in all of these areas is that outcomes will be as good as possible.

This interpretation of Consequentialism is justified firstly by the fact that this is what its leading contemporary exponents take to be its central claim. The quotation given in the previous paragraph was taken from Parfit's work and Pettit also endorses this as the central claim of Consequentialism. ${ }^{\text {viii }}$ Hare argues for its role as a justificatory doctrine at least at the intuitive level of moral thinking. At the critical level, he does 
suggest applying Consequentialism to the direct evaluation of actions but only because this is the way that he considers outcomes will be as good as possible. ${ }^{\mathrm{ix}}$

This last point highlights the second justification for the claim that Consequentialism is essentially a doctrine that justifies options in terms of maximising best outcomes. When it is applied specifically to acts, rules, motivations etc., the justification is always that applying it in this way will lead to outcomes being maximised. They are just being proposed as different vehicles that will perform this task. In other words, Consequentialists could all agree that their doctrine is ultimately that outcomes be as good as possible but disagree on how this central aim is to be achieved. In the light of this, we shall fail to get at the heart of the contrast between these three theories if we, for example, translate them all into an act formulation and then seek to compare and contrast them. ${ }^{\mathrm{x}}$ An act formulation of Consequentialism does not give us the essence of the doctrine.

Also, since different features are taken to constitute good outcomes in different versions of Consequentialism, contrasts which rely on one particular specification of a good outcome will not capture what is in common to all versions of the theory. Hence, accounts which try to get at the heart of the difference between these three approaches by taking as their starting point Act Utilitarianism will fail to reflect what is central to the Consequentialist approach in both of the above ways by concentrating on an act formulation and happiness as what has intrinsic value.

If it is agreed that this captures the essence of Consequentialism, then it is apparent that understood in this way Consequentialism is not a complete ethical theory. To 
provide a complete answer even to just the one ethical question of justification it will need to be combined with a value theory about what is good. Hence Consequentialism neither tells us directly how we ought to act, what motivational doctrine we should adopt, what sort of character we ought to develop and nor does it provide an account of what is to count as a good outcome. Also, in terms of this latter question about which it is silent, it is also silent about how we should attempt to justify any answer to the question of what is fundamentally of value. Considering Consequentialism alone, we just know that this fundamental value of goodness will not be justified in terms of outcomes being as good as possible. We are given no positive guidance about how to justify what has intrinsic goodness other than knowing that the justification cannot be a Consequentialist one. Consequentialist theories have incorporated many different positive accounts ranging from appeals to “intuition"xi " "larger meaning of the word 'proof", "xii to linguistic intuitions ${ }^{\text {xiii }}$ to justify different claims about what has intrinsic goodness. It therefore seems to have very little to offer even in this reduced form.

However, maybe it can be enriched, as Pettit suggests, by combining it with other ethical theories which provide answers to ethical questions about which Consequentialism is silent. What would this suggestion look like if we try to combine Consequentialism with Virtue Ethics? Presumably, the character that a virtuous agent should have would be one that would produce outcomes as good as possible. The strangeness of this suggestion highlights another feature of the characterisation of Consequentialism given above. It is essentially a doctrine about bringing something about - about doing rather than being. It is about promoting an end that does not exist. It is this feature that captures the essential strangeness of the suggestion and not the 
fact that the virtues are being valued instrumentally. Some theories of Virtue Ethics take the virtues to have intrinsic value but other theories of Virtue Ethics are proposed where the virtues are justified as, for example, being necessary for human flourishing.

To take an example of applying Consequentialism to the question of what sort of character the virtuous person should have, I shall consider courage. The justification for the virtue of courage would be that expected outcomes would be as good as possible if a person has the virtue of courage. However, if we consider two identical situations except that in one the person is courageous and in the other the person is foolhardy, then we can see the inadequacy of using Consequentialsim as a justificatory doctrine for the character that a virtuous agent should have. In both these situations, the two people rush to the edge of a cliff and prevent a small child from falling over the edge. In both cases we can assume that outcomes were as good as possible but that either makes the character of the person performing the action irrelevant or we shall be forced to the conclusion that foolhardiness is also a virtue like courage since outcomes are as good as possible. In other words, since outcomes were as good as possible that justifies the option as being the right option irrespective of the character of the agent.

Alternatively, if outcomes being as good as possible is taken to justify the possession of courage as a virtue this will fail since the same argument could be used to justify the possession of foolhardiness. The fact that outcomes were as good as possible does not, in itself, indicate the presence of courageousness as opposed to foolhardiness. Although it might be described as courageous to save a small child from falling from the edge of the cliff, this does not guarantee the presence of the virtue of courage as 
opposed to foolhardiness. As Aristotle makes clear, the performance of a virtuous action is a necessary condition for the existence of a virtuous state but not in itself sufficient. He writes in the Nicomachean Ethics, “...he who stands his ground against things that are terrible and delights in this or at least is not pained is brave, while the man who is pained is a coward.”xiv

So although Consequentialism is being put forward as a justificatory doctrine only, with the implication that it can be combined with certain aspects of other theories, the nature of the sort of justification proposed debars it from answering the question, “What sort of character would the virtuous agent have?” This question is irrelevant within Consequentialist theories since the focus is on outcomes to be brought about.

Pettit is also wrong when he suggests that if Consequentialism is just setting out to answer the question of justification then it can "feel open and uncommitted" and that "Consequentialists have much to learn from other approaches, not because of taking mistaken lines on various ethical questions, but because of not taking any line on those questions."xv Ethical questions do not form some unconnected group. Questions about the character of agents, motivation, what I ought to do and justification are at least linked to the extent that answers given in one of these categories have implications for answers to other ethical questions.

Indeed, elsewhere Pettit appears to recognise this point, at least implicitly, when he does recognise what is a major difference between a Consequentialist approach and a Virtue Ethics approach. This is that "almost all virtue ethicists presume that the point is to instantiate the virtues not to maximise them."xvi This highlights that the "pick 
and mix” approach advocated by Pettit has inherent flaws and cannot be adopted as a way of enriching Consequentialism.

Another illustration will show the difficulty of combining Consequentialsim with motivational doctrines that are distinct from the motivation of producing the best expected outcome. Pettit argues that Consequentialsim, "allows other subjects to enter directly into people's individual concerns. It allows the concerns that move people to motivate them independently of moralistic mediation. And it allows and encourages people to be spontaneous, non-calculative servants of the ends they embrace.”xvii

In other words, the justificatory doctrine of Consequentialism specifically encourages decision procedures that are not based on consequentialist calculations.It encourages motivations of direct concern for others, independently of viewing this as a means to maximise expected outcomes. However, this is not to adopt these other motivational doctrines and concerns in their original forms. The acceptance of these is always based on the claim that they will produce the best expected outcome. If they cease to do this, then they will be rejected. They cannot have the same intrinsic worth that is accorded to them from a non-Consequentialist perspective since they are ultimately only valued instrumentally. Although, the best expected outcome might be achieved if we forget that these motivational doctrines only have instrumental value, as has been pointed out by Parfit ${ }^{\text {xviii }}$ the justification cannot be entirely forgotten. If Consequentialism were wholly self-effacing, then we would no longer have a rationale for changing motivational doctrines since the justification would have been entirely concealed. 
Hence, the motivations that we have picked to combine with Consequentialism on the ground that they produce the best expected outcome, no longer have the intrinsic worth that is normally accorded to them. The skill necessary to pretend that they do, in order that outcomes be maximised, coupled with the knowledge that they are really only of instrumental value, is the sort of mental gymnastics that Consequentialsim requires.

These two illustrations of the "pick and mix" approach suggested by Pettit highlight the problems with supposing that Consequentialism can just be viewed as the answer to the question of the justification of rightness whilst remaining uncommitted with respect to other ethical questions. It is an impoverished doctrine that cannot be enriched by taking answers from other ethical theories to the ethical questions that it no longer answers directly.

\section{Virtue Ethics}

I suggested above that the central activity in Virtue Ethics is the development of a virtuous character. Each person should have as their central concern the development of their character. However, unlike Consequentialist Ethics, although the development of the agent's own character is the central concern, Virtue Ethics does provide answers to other ethical questions as well. For example, adherents of Virtue Ethics can provide a characterisation of what counts as a right action whilst recognising that judgements about character are prior to judgements about the rightness or wrongness of actions. 
As a starting point, I shall take the formulation, quoted earlier, that Rosalind Hursthouse gives of what would count as a right action in virtue ethical theories. Hursthouse writes, “An action is right iff it is what a virtuous agent would characteristically (i.e. acting in character) do in the circumstances." ${ }^{\text {xix }}$ Now this formulation requires some careful examination. First, as it stands it would not appear to be a necessary condition of the rightness of an action that it is performed by a virtuous agent. This is because Hursthouse talks about what a virtuous agent would characteristically do. Therefore, to return to an example earlier in the paper, a foolhardy person could rescue the small child from the edge of the cliff and thereby perform a right action since it is the action that the courageous person would characteristically do.

In general then, irrespective of an agent's character, if an agent performs an act that would be the act that a virtuous agent would perform if acting in character, then this would be the right action. However, this is surely to miss the central point of a Virtue Ethics theory which is that what makes an action right is that it is done by a virtuous agent. To take another example, we have two cases in each of which an agent helps an elderly person across the road. This might be what a benevolent agent would do in these sorts of circumstances if acting in character but if one of these agents is not a benevolent agent then the action will not be the right action. In other words, we might superficially have the same action being performed but this would not be the case if one of the agents is a virtuous agent and the other is not.

So a reformulation of Hursthouse's position is necessary to remove this ambiguity. Perhaps the following will capture what is distinctive of what will count as a right 
action within Virtue Ethics. A necessary and sufficient condition of an action being right is that it be performed by a virtuous agent acting in character This formulation has removed the possibility that there could be an extensional equivalence between actions performed by virtuous agents and actions performed by agents who lack the virtues but who act as a virtuous agent would if acting in character.

However, it is possible that this second formulation is also ambiguous. Michael Slote considers that there can be two different versions of Virtue Ethics depending on how we interpret the above formulation. We could either be saying that virtuous agents are able to perceive or are sensitive to something in actions that makes them right. That is, there are features that make an action right and virtuous agents perceive these features. Alternatively, one could argue that what makes the action right is not these features but the fact that the virtuous agent, acting in character, chose this action as the right action. It is this choosing that constitutes the rightness of the action. He calls the former an act-based Virtue Ethics and the latter agent-based. Slote writes of agent-based Virtue Ethics that, "It must derive its evaluations of human actions, whether aretaic or deontic, from independent and fundamental aretaic characterisations of the inner traits or motives of individuals or of the individuals themselves" $\mathrm{xx}$

In both these versions of Virtue Ethics, the character of the virtuous agent is still primary. The virtuous character in choosing makes the action right or the virtuous character is sensitive to features in the situation that make the action right. In both cases, the primary aim will be for the agent to develop a virtuous character. This 
virtuous character will either in itself make the actions she performs right or will enable her to perceive features in a situation that make an action right.

\section{$\underline{\text { Kantian Ethics }}$}

Like Virtue Ethics, Kantian Ethics is also able to answer the question of what makes an action right whilst still taking as the central activity the development of a good will. This might seem an obvious claim to those who take Kant's primary concern to be the evaluation of actions. However, recent interpretations have argued against this traditional interpretation. In what follows, I shall be providing my own justification of the centrality of the development of a good will in Kant's ethics rather than the evaluation of actions. However, like Virtue ethics, this does not preclude a Kantian answer to the question of what makes an action right.

Kant starts the Groundwork of the Metaphysics of Morals with the claim that the only thing that has intrinsic goodness is a good will. He writes, "There is no possibility of thinking of anything at all in the world, or even out of it, which can be regarded as good without qualification, except a good will»xxi

This good will is developed by acting on maxims that can pass the test given by Kant in the Categorical Imperative, "I should never act except in such a way that I can also will that my maxim should become a universal law.”xxii Hence we have an account of what actions to perform, at least to the extent of a test for any proposed maxims that we might put forward. Acting in this way is how Kant understands the virtuous agent. He writes, "Now the capacity and considered resolve to withstand a strong but unjust opponent is fortitude (fortitudo) and, with respect to what opposes the moral 
disposition within us, virtue (virtus, fortitudo moralis). So the part of the general doctrine of duties that brings inner, rather than outer, freedom under laws is a doctrine of virtue. “xxiii

The virtuous agent is one who acts as closely as possible to the good will by overcoming inclinations and acting on maxims that can become universal laws. The fact that the good will and virtue are defined with respect to the moral law, does not invalidate the claim that Kant's central ethical activity is the development of a good will. Just as there are standard versions of virtue ethics that do not take the virtues to have intrinsic value but rather ground the virtues in the idea of human flourishing, so a virtuous character can be explained in terms of the requirements of the moral law.

Where this suggestion does sound strange is if it is taken as axiomatic that virtue ethics should contain no reference to rules or laws or principles but instead rely on notions of sensitivity that cannot be unpacked in terms of rule following. However, this claim can be attacked on at least two grounds. First, there are exponents of virtue ethics who argue for principles within virtue ethics. For example, Hursthouse claims, "that virtue ethics not only comes up with rules (the v-rules, couched in terms derived from the virtues and vices), but further, does not exclude the more familiar deontologists' rules.”xxiv The first sort of rules will be of the sort, 'Act charitably', 'Do not act dishonestly” and the second sort would be, 'Do not tell a lie'. This second sort would be backed up by an appeal to a virtue or vice. In the case of the example given, the reason that you must not tell a lie is because it would be dishonest. 
The second ground for attacking this claim is that the opposition between virtue ethics and rules is often based on a view of rules as algorithms for providing an account of what is right. McDowell seems to implicitly make this move when he argues for the non-reduction of the sensitivity of the virtuous person to a list of rules. He writes, "If one attempted to reduce one's conception of what virtue requires to a set of rules, then, however subtle and thoughtful one was in drawing up the code, cases would inevitably turn up in which a mechanical application of the rules would strike one as wrong - and not necessarily because one had changed one’s mind; rather, one's mind on the matter was not susceptible of capture in any universal formula.”xxv

Now it is not necessary to hold this conception of rules and it is at least arguable that Kant did not take rules in this way. In the Metaphysics of Morals Kant specifically denies this rote application of rules when he examines cases of conflict. In such cases, we do not say that both rules apply but we recognise that there are conflicting grounds and that judgement is required to see which applies. ${ }^{\text {xxvi }}$ This is made more specific when he considers the casuistical questions where it becomes clear that the rules or principles supply guidelines rather than algorithms and require judgement for interpretation. Kant writes, "Is it murdering oneself to hurl oneself to certain death (like Curtius) in order to save one’s country? Or is deliberate martyrdom, sacrificing oneself for the good of all mankind, also to be considered an act of heroism?»xxvii

\section{Virtue Ethics or Kantian Ethics}

If then we accept that both Virtue Ethics and Kantian Ethics are more wide ranging than Consequentialism and that both start from a position where the central activity is some sort of development of the agent, which is to be preferred as an approach to 
ethical questions? If the central activity is taken to be some sort of concern by the agent for her character or good will, are there compelling grounds for adopting a virtue ethics approach as opposed to a Kantian approach?

I shall argue that there is at least one ground for preferring Kantian Ethics which becomes evident when considering a common criticism that can be made to both Kantian Ethics and Virtue Ethics as I have characterised them. The criticism is that so characterised they are open to the self-centredness objection. If we are to keep our own character development or the development of a good will at the centre of ethical concern, isn’t this unjustifiably self-centred. Shouldn't concern for others figure in a moral theory?

Now, it is important to be clear about the precise nature of this objection. For example, it should not be conflated with the claim made by Solomon that, “This asymmetry between my attitude towards my own character and my attitude towards the character of others is, it seems to me, ineliminable within virtue ethics."xxviii Solomon extends this point to Kantian Ethics and takes it to imply the selfcentredness objection. Now, while I agree that in the case of both Kantian Ethics and Virtue Ethics, as I have described them, there is an asymmetry in my attitude towards my own character and my attitude towards the character of others, this can be accepted without accepting that Kantian Ethics and Virtue Ethics are open to the selfcentredness objection. From the claim that a different attitude is taken to my own character it does not follow that too much attention is being paid to our own character development. 
I shall argue that whilst agreeing with Solomon that there is this "ineliminable" asymmetry in attitude this does not imply the self-centredness objection in the case of Kantian Ethics since this theory necessarily incorporates the recognition that others are also developing a good will. In the case of Virtue Ethics, this recognition of the character development of others is contingent and thus Virtue Ethics can be liable to the self-centredness objection.

To begin with, it is important to note, as Solomon remarks, that the charge of selfcentredness cannot be answered by pointing to the fact that I shall be acquiring otherregarding virtues as well as self-regarding virtues. This still does not incorporate a concern for other agent's character development in the same way as I have a concern for my own character development. The fact that I might acquire the virtues of kindness or justice might ensure that I treat others in this way but to exhibit kindness to someone is not the same as being concerned to develop that virtue, for example, in their character.

However, Kant is suggesting something more than this. To understand this, it is necessary to remember that Kant puts forward two obligatory ends which he calls duties of virtue. ${ }^{\text {xxix }}$ These are distinguished from ends that we might have contingently and they are the duties of self perfection and the duty to seek the happiness of others. Kant explicitly denies that we have a duty to make another person's perfection our end and also denies that we have a duty of happiness to ourselves. In the latter case, we do not have a duty to promote our own happiness because what we already want cannot be a duty. In the former case, we cannot have a duty to seek another person's perfection because this is something that is under the 
autonomous control of each agent. It is under the control of each agent to set her own goals rather than have someone else set them for her.

Now, this supports Solomon's position that Kant is advocating a different attitude to self perfection than to other's perfection. Indeed, Solomon brings forward this precise evidence to support his claim that Kantian Ethics shares the same asymmetry that Virtue Ethics does. However, this misses the fundamental point about the Kantian doctrine because the recognition that other agents are also embarked on the task of the cultivation of a good will is essential to an understanding of Kantian Ethics. In this respect, then, the different attitude does not imply that too much attention is being paid to self-development. The acceptance of the different attitude does not make Kantian Ethics liable to the self-centredness objection.

To understand this point it is necessary to explain precisely how to understand this asymmetry between my attitude to my own character and my attitude to the character of others. In both Virtue Ethics and Kantian Ethics there is a different attitude to self development than to that same development in others. Virtue Ethics, has as its essence the development of the individual's own character and there is no essential mention of others in this development. Others figure just as the recipients of the other-regarding virtues that I acquire . In contrast, on a Kantian account although the duty of perfection is limited to the self, there is also essentially the recognition that other human beings are also seeking their own perfection. The recognition of this generates certain duties that I owe to others. These are duties that incorporate my recognition that they are also agents who are setting their own ends and seeking to develop their own good will. Negative duties not to obstruct them in this task and also 
positive duties of assistance are thus generated in virtue of this recognition of them as agents with ends. This is not an optional extra on the Kantian account since the development of the agent's own good will has to be considered alongside the constraints implicit in the recognition that others are also developing their own good will.

The key then to understanding this asymmetry and recognising that it does not imply the self-centredness objection in the case of Kantian Ethics although it could in the case of Virtue Ethics can be seen in the following example about Christian love taken from Solomon's article. If we consider that the acquisition of Christian love is a virtue then this “requires me to attend to the wants, needs and desires of others. But doesn't this suggest that I regard others as less morally important than myself? Satisfying their needs is good enough for them, but I require of myself that I become a loving person.”xxx There is no recognition in my attitude that they are also agents embarked on the task of acquiring virtues. They are just viewed as recipients of my loving and kind Christian virtue.

In contrast, in the Kantian account although there is an asymmetry in the sense that I do not have the same attitude to the development of good will of others as I do to the development of my own, there is built in the recognition that others are also embarked on this task and this generates obligations within me. The self -centredness objection which can apply to Virtue Ethics cannot apply to Kantian Ethics.

My argument is that the recognition that others are also developing a good will is necessary to Kantian Ethics but the recognition that others are also developing a 
virtuous character is, at best, only contingently present in Virtue Ethics. There is nothing necessary in my development of a virtuous character that requires that I take into account that others are also embarked on this task. In contrast, within Kantian Ethics the development of a good will cannot be explained in isolation from the fact that others are also developing a good will.

Now, even if the above is accepted it might be argued that there are other points that could be put forward to support a Virtue Ethics approach as opposed to a Kantian approach. One that was hinted at during the course of the paper was the incorporation within Kantian Ethics of principles or rules which might be deemed objectionable by supporters of certain forms of Virtue Ethics. I have not time to debate the merits of the debate between Virtue Ethics and Kantian Ethics on other fronts. However, I think that a case can be made for the central importance of the point that I have discussed. In an ethical theory, concern for others must go beyond just viewing them as recipients of our other-regarding virtues. Their development must be considered hand in hand with our own. Therefore, if the characterisation that I have given of the central activity of Virtue Ethics is accepted, this criticism of the approach strikes at the very essence of the theory.

\section{Conclusion}

The opposition between Virtue Ethics, Kantian Ethics and Consequentialism as described in much contemporary literature has been shown to be misplaced. Virtue Ethics has been taken to be in opposition to Kantian Ethics and Consequentialism because of its concentration on character development rather than the Kantian or Consequentialist's concentration on what makes an action right. 
I have argued that this is not the correct way to describe those theories.

Consequentialism is essentially just a doctrine about what justifies the right option and cannot "pick and mix" from other ethical theories to provide answers to other ethical questions. Both Kantian and Virtue Ethics have the development of the agent as their focus whilst still providing answers to the question of what makes an action right. However, to avoid the charge of self-centredness, an ethical theory needs to be developed that essentially incorporates the recognition that others are also, as moral agents, embarked on the task of moral self perfection. Kantian Ethics does this and this is one reason to prefer Kantian Ethics to Virtue Ethics.

\section{Dr. Jane Singleton}

\section{Principal Lecturer in Philosophy}

\section{University of Hertfordshire}

\section{September 1999}

\footnotetext{
${ }^{\text {i }}$ Louden, R.B. (1997) “On Some Vices of Virtue Ethics” in Virtue Ethics: A Critical Reader Statman, D (ed), Edinburgh University Press, Edinburgh, p.191.

ii Baron, M (1997) "Kantian Ethics” in Three Methods of Ethics Baron M, Pettit, P, and Slote,M, Blackwell, Oxford, p. 4

${ }^{\text {iii }}$ Pettit, P (1997) :"Reply to Baron and Slote” in Three Methods of Ethics Baron M, Pettit, P and Slote, M, Blackwell, Oxford, p. 256

iv Pettit, P (1997) “The Consequentialist Perspective” in Three Methods of Ethics Baron M, Pettit, P and Slote, M, Blackwell, Oxford, p.160

v Kant, I (1785) Grounding for the Metaphysics of Morals in Ellington, J.W. (trans) (1993) Grounding for the Metaphysic of Morals Hackett, USA, 396.

${ }^{v i}$ Parfit, D (1984) Reasons and Persons Clarendon Press, Oxford, p. 24

vii Slote argues for a satisficing form of Consequentialsim in Slote, M (1985) Common-Sense Morality and Consequentialsim RKP, London. Pettit, however, considers that it must be stated in a maximising form in Pettit,P (1997) “The Consequentialist Perspective”. p.128.

viii Pettit, P (1997) "Reply to Baron and Slote” in Three Methods of Ethics Baron, M, Pettit, P and Slote, M, Blackwell, Oxford, p. 252.

ix Hare, R.M. (1989) Moral Thinking : Its Levels, Method and Point Clarendon, Oxford.

x Hursthouse, R, (1997) “Virtue Theory and Abortion” in Virtue Ethics Crisp, R and Slote, M (eds), O.U.P. Hursthouse compares Virtue Ethics, Deontological Ethics and Utilitarian Ethics by considering them all in an act formulation.

xi Moore, G.E (1903) Principia Ethica C.U.P
} 
xii Mill, J.S (1861) “Utilitarianism” in Warnock,M (1968) Utilitarianism: John Stuart Mill Fontana, Collins, London

xiii Hare R,M (1981) Moral Thinking: Its Levels, Method and Point, Clarendon, Oxford

${ }^{\text {xiv }}$ Ross, W.D (and Urmson, J.O), revised Barnes, J , trans., (1984) Oxford Aristotle : Nicomachean Ethics, 1104b

${ }^{x v}$ Pettit, P (1997) "Reply to Baron and Slote" in Three Methods of Ethics Baron, M, Pettit, P and Slote,M, Blackwell, Oxford, pp 253-254.

xvi Pettit, P (1997) "Reply to Baron and Slote" in Three Methods of Ethics Baron, M, Pettit, P and Slote, M, Blackwell, Oxford, p.259.

xvii Pettit, P (1997) "The Consequentialist Perspective" in Three Methods of Ethics Baron, M, Pettit, P and Slote, M, Blackwell, Oxford, p.102

xviii Parfit, D (1984) Reasons and Persons, Clarendon, Oxford, p. 41.

xix Hursthouse, R (1998) "Normative Virtue Ethics" in How Should One Live?: Essays on the Virtues Crisp, R (ed) OUP, Oxford, p. 22

xx Slote, M (1997) "Virtue Ethics" in Three Methods of Ethics Baron, M, Pettit, P and Slote M, Blackwell, Oxford, p. 206

${ }^{x x i}$ Kant, I (1785) Grounding for the metaphysics of Morals in Ellington, J.W. (trans.) (1993)

Grounding for the Metaphysics of Morals Hackett, USA, 393.

xxii ibid., 402

xxiii Kant, I (1797) The Metaphysics of Morals in Gregor, M (trans) (1991) The Metaphysics of Morals C.U.P, 380 .

xxiv Hursthouse, R (1998) “Normative Virtue Ethics” in Crisp, R (ed) How Should One Live?

Clarendon, Oxford, p.27

${ }^{\mathrm{xxv}}$ McDowell, J (1997) “Virtue and Reason” in Crisp, R and Slote, M (eds.) Virtue Ethics , O.U.P., p. 148.

${ }^{x x v i}$ Kant, I (1797) Metaphysics of Morals in Gregor, M (Trans) The Metaphysics of Morals C.U.P, 224.

xxvii ibid., 423.

xxviii Solomon, D (1997) “Internal Objections to Virtue Ethics” in Virtue Ethics: A Critical Reader Statman, D (ed), Edinburgh University Press, Edinburgh, p.172.

xxix ibid, 386.

xxx Solomon, D. (1997) “Internal Objections to Virtue Ethics” in Statman, D (ed) Virtue Ethics: A

Critical Reader, Edinburgh University Press, Edinburgh, p. 172. 